\title{
The importance of informal carers for primary health care
}

Demographic ageing in Europe leads to a growing incidence of age-related diseases, a growing demand for care and a real sustainability challenge for our social and health-care systems. Against this backdrop, community care has become a prominent EU priority in the last few years and the shift towards home-based care is seen as a practical measure to contain the costs of services while also supporting widespread preferences among older people for being cared for in their own home (European Union, 2012). In most European countries, a large part of long-term care for older people is provided by informal carers. Even in countries with a well-developed supply of formal long-term care, using narrow definitions of informal carers, their number is estimated to be at least twice as big as the formal care workforce. According to recent EU-funded research, informal carers across the EU provide over $80 \%$ of all care, with women providing approximately two-thirds of care mainly as daughters (in law) and wives/ partners. Advances in medicine also mean that carers find themselves having to deliver more and more sophisticated levels of care, with very little training and minimal support (Rodrigues and Hoffmann, 2010).

\section{Carers: what are the issues?}

Estimates of the number of carers in the EU vary according to the definitions of the EU and of carers that are used, and the methods used to identify carers in EU-wide data, in particular, reflect the process of enlargement that has taken place since 2003. However, the significant differences in patterns of family obligation and formal welfare services between the older and newer member states mean that figures from the EU15 (ie, the number of member countries in the European Union before the accession of 13 candidate countries in 2004, 2007 and 2013) cannot simply be scaled up to reflect current EU membership. Besides, the prevalence and consequences of informal care in the older and newer member

(C) Cambridge University Press 2016 states seem to be shaped by the type of welfare system in place and therefore appear to be very different. As a result, estimating the total number of carers across the EU is a complex process (Triantafillou et al., 2010).

Eurocarers, the EU network working with and for carers, defines carers as persons of all ages who provide care (usually unpaid) to someone with a chronic illness, disability or other longlasting health or care need, outside a professional or formal employment framework. ${ }^{1}$ Based on this definition and according to the data collected through the European Quality of Life Survey, it is estimated that there are more than 100 million carers in the EU today - about a fifth of the total European population (Eurofound, 2012). Estimates also suggest that the economic value of unpaid informal care - as a percentage of the overall cost of formal long-term care provision - in EU Member States ranges from 50 to $90 \%$ - a huge contribution in times of austerity and tight health and social budgets (Giannelli et al., 2012).

From the above, it is clear that carers are an inherent as well as an indispensable part of the provision, organisation and sustainability of health and social care systems. They will become even more important in view of the changing health and care needs, due to the ageing of society and the increasing prevalence of frailty and chronic disease. However, this precious resource is under pressure: the combination of various demographic and socio-economic developments - such as lower birth rates, the trend towards smaller families, increasing mobility (leading to greater physical distances between relatives), the rising number of women entering the labour market and a prolonged working life due to delayed retirement (partly following explicit policies aiming at increasing labour force participation of women and older workers) - is rapidly leading to increased

\footnotetext{
${ }^{1}$ Enabling carers to care - Eurocarers' proposal for an EU-level strategy in support of informal care provision - https://www. eurocarers.org/userfiles/files/policy/Carers $\% 20$ strat $\% 20 \mathrm{dr} 12 \%$ 2013Final.pdf
} 
strain on carers, as a direct result of the decreasing unpaid care potentials. In addition, in many countries, governments aim to decentralise care provision, and count on society to step up to the challenge. Moreover, these developments are being compounded by increasing shortages of formal caregivers, and this is rapidly becoming a major issue in the majority of EU Member States.

While caring for a loved one can be a source of personal satisfaction and emotional gratification. Caring can have - if not adequately supported many challenging consequences for carers:

- It can impact on the (physical and mental) health and well-being of carers themselves. The prevalence of mental health problems among informal carers is $20 \%$ higher than among non-carers, and particularly high for people who provide very intensive care $(>20 \mathrm{~h} /$ week $)$. Depressive disorders, anxiety, anger and hostility are frequently associated with heavier caring duties. Caring also brings various adverse effects on physical health, as caregivers are less likely than others to meet their own health needs. This can result in harmful habits and lifestyles (smoking, inadequate food or sleep habits) and failure to take preventive health measures (such as medical consultations) (Colombo et al., 2011).

- It can lead to difficulties in relation to balancing paid work with care responsibilities, which can impact on labour market participation. Many carers of working age (mainly women) cannot cope with these multiple pressures and are forced to reduce or give up work - which has a negative impact on their social protection rights and hence, their financial situation later in life. Carers often face financial difficulties and poverty, due to cutbacks in social provision and direct costs of care (eg, medication, heating, special diet), medical devices, home adaptations and payments for formal care (Viitanen, 2005).

- It can impact the natural socialisation processes as well as the formal education, family relationships and employment prospects of young carers - that is children and young people under the age of 18 who provide care for a parent or relative in the community, usually within their own home.

- Finally, countries which rely predominantly on informal carers are likely to find it significantly more difficult to guarantee equality of access to care, because not all needy people have family members able or willing to be carers (European Union, 2014).

All of the above underline the need for actions aimed at building and strengthening carer resilience and putting support in place that enables them to continue to care.

\section{Relevant EU policy domains with a bearing on carers}

Despite the obvious importance and contribution of carers as outlined above - both to care supply as well as to the economy and society as a whole their interests are rarely considered in policies that impact on them in a consistent and acrossthe-board manner: health, social, education, employment, social security, transport and housing policies, all come into play in different ways. Yet, all member states are facing comparable challenges in terms of long-term care provision, both with respect to the development and implementation of effective care provision models as well as in relation to financial sustainability. While care provision differs greatly between (and sometimes within) member states, it is clear that all countries need the resource provided by informal carers to prevent a collapse of the entire care system. Links between health care and long-term social care can be weak and their full integration is rare outside a few member states. The distinction between health care and long-term social care is rooted in very real differences: health care, for example, is entirely professional, whereas longterm social care in many countries relies heavily on family and informal carers. However, in the future, the key role of health care in prevention and rehabilitation will make effective coordination essential, and the traditional distinction between health and social care is likely to become increasingly blurred, as the social care sector is obliged to develop expertise in managing the medication and other treatment of long-term conditions such as dementia and diabetes. In order to contribute to this integration process, informal carers should have ready access to information from doctors, nurses and therapists about available medical services and how to use them; publicly funded home care services should act as intermediaries between professional health-care services and 
home-based informal carers; and users and carers should be involved from the outset in the assessment of needs and the allocation of tasks.

\section{What can primary health-care professionals do now to support carers?}

Informal carers are vital, both to the care of patients in the community and the economy of EU countries, and primary health-care professionals are in the forefront of their support. Although questions remain about effective interventions, many things can be done now to support informal carers - most of which are neither time consuming nor expensive in terms of resources.

- Acknowledge carers, what they do and the problems they have.

- Flag the notes of informal carers so that in any consultation you are aware of their circumstances.

- Treat carers as you would other team members and listen to their opinions.

- Include them in discussions about the person they care for.

- Give carers a choice about which tasks they are prepared to take upon themselves.

- Ask after the health and welfare of the carer as well as the patient.

- Provide information about the condition the person the carer is looking after suffers from.

- Provide information about being a carer and support available.

- Provide information about benefits available.

- Provide information about local services available for both the person being cared for and the carer.

- Be an advocate for the carer to ensure services and equipment appropriate to the circumstances are provided.

- Liaise with other services.

- Ensure staff are informed about the needs and problems of informal carers.

- Respond quickly and sympathetically to crisis situations (Simon, 2001).

If society expects informal carers to keep providing care - and it does, their vital role and contribution must be recognised and their support needs must be addressed. After all, as Rosalyn
Carter, Former First Lady of the United States once said: there are four kinds of people in the world - those who have been carers, those who currently are carers, those who will be carers and those who will need carers. This concerns us all!

Stecy Yghemonos Executive Director Eurocarers - European Association Working for Carers

Brussels, Belgium

\section{References}

Colombo, F. et al. 2011: Help wanted? Providing and paying for long-term care. Retrieved 11 October 2016 from http:// www.oecd.org/health/longtermcare/helpwanted

Eurofound. 2012: European Quality of Life Survey 2012. Retrieved from http://www.eurofound.europa.eu/surveys/ european-quality-of-life-surveys/european-quality-of-lifesurvey-2012/eqls-2012-reports-and-policy-briefs-trackingquality-of-life-in-europe

European Union. 2012: Long-term care for the elderly provisions and providers in 33 European countries. Luxembourg: Publications Office of the European Union. Retrieved from http://ec.europa.eu/justice/gender-equality/ files/elderly_care_en.pdf

European Union. 2014: Adequate social protection for long-term care needs in an ageing society. Luxembourg: Publications Office of the European Union. Retrieved from http://ec. europa.eu/social/BlobServlet?docId=12808\&langId=en

Giannelli, G.C., Mangiavacchi, L. and Piccoli, L. 2012: GDP and the value of family caretaking: how much does Europe care? Applied Economics 44, 2111-31.

Rodrigues, R. and Hoffmann, F. 2010: Informal carers: who takes care of them?, European Centre for Social Welfare Policy and Research. Retrieved from http://www.euro. centre.org/data/1274190382_99603.pdf

Simon, C. 2001: Informal carers and the primary care team. British Journal of General Practice 51, 655-57.

Triantafillou, J., Naiditch, M., Stiehr, K.R.K., Carretero, S, Di Santo, T.E.P., Bednarik, R., Ceruzzi, L.B.F., Cordero, L., Ferrando, T.M.M., Mingot, K. and Vlantoni, J.R.D. 2010: Informal care in LTC - European overview paper, Interlinks report. Retrieved 11 October 2016 from http://interlinks.euro. centre.org/project/reports; www.eurocarers.org.

Viitanen, T. 2005: Informal elderly care and female labour force participation across Europe. ENEPRI Research Report No. 13, July. Retrieved from http://www.enepri.org/files/ Reviser/enepri-tarja.pdf 